\title{
Innovative Research on the Development of Game-based Tourism Information Services Using Component-based Software Engineering
}

\author{
Wei-Hsin Huang ${ }^{*}, 1$, Huei-Ming Chiao ${ }^{1}$, Wei-Hsin Huang ${ }^{2}$ \\ ${ }^{1}$ Graduate Institute of Design Science, Tatung University \& Department of Digital Game and Animation Design Taipei University of \\ Maritime Technology, Taipei, Taiwan, R.O.C. \\ ${ }^{2}$ Department of Media Design, Tatung University, Taipei, Taiwan, R.O.C.
}

\begin{tabular}{l} 
A R T I C L E I N F O \\
\hline Article history: \\
Received: 14 December, 2017 \\
Accepted: 18 January, 2018 \\
Online: 10 February, 2018 \\
\hline Keywords: \\
Digital Guide \\
Game-Based Learning \\
Component-based Software \\
Engineering
\end{tabular}

\section{Introduction}

In the United States, museums and historical sites generated 15 billion U.S. dollars in revenue in 2017 [1]. With the rapid development in information technology, the diversification and popularization of mobile carriers have made for rich digital content development. The Taiwan Tourism Bureau survey analysis also shows that cultural tourism has become an important tourism trend. The integration of multi-material, cross-platform and crossindustry values has become another focus of the content industry. Digital guides and online tourism maps of museums and historical

*Corresponding Author: Wei-Hsin Huang, Tatung University, Taipei, Taiwan, R.O.C., Email: wshuang@ttu.edu.tw

\begin{abstract}
A B S T R A C T
In recent years, a number of studies have been conducted exploring the potential of digital tour guides, that is, multimedia components (e.g., 2D graphic, 3D models, and sound effects) that can be integrated into digital storytelling with location-based services. This study uses component-based software engineering to develop the content of game-based tourism information services. The results of this study are combined with $3 D$ VR/AR technology to implement the digital 2D/3D interactive tour guide and show all the attractions' information on a service platform for the gamification of cultural tourism. Nine kinds of game templates have been built in the component module. Five locations have completed indoor or external $3 D$ VR real scenes and provide online visitors with a virtual tour of the indoor or outdoor attractions. The AR interactive work has three logos. The interactive digital guide includes animated tour guides, interactive guided tours, directions and interactive guides. Based on the usage analysis of the component databases built by this study, VR game types are suited to object-oriented game templates, such as the puzzle game template and the treasure hunt game template. Background music is the database component required for each game. The icons and cue tones are the most commonly used components in 2D graphics and sound effects, but the icons are gathered in different directions to approximate the shape of the component to be consistent. This study built a vivid story of a scene tour for online visitors to enhance the interactive digital guide. However, the developer can rapidly build new digital guides by rearranging the components of the modules to shorten the development time by taking advantage of the usage frequency of various databases that have been built by this study to effectively continue to build and expand the database components. Therefore, more game-based digital tour guides can be created to make better defined high-quality heritage attractions understood.
\end{abstract}

sites' interactive tourist information services have gradually changed reading habits in recent years, replacing the hard copy of tourism guide maps. Since the development of the global digital economy, the output of digital content industries in Taiwan [2, 3] has reached over a $10 \%$ annual growth rate in recent years and a value of about 32 billion U.S. dollars in 2015. Based on the advantage of many excellent manufactories of information and communication technology in Taiwan, virtual reality technology has been regarded as an important driver of the digital economy. Applications such as commercial games, knowledge learning, and museum guides have increasingly introduced virtual reality, augmented reality, and mixed reality in Taiwan. For example, HTC and Foxconn Technology Group announced the first 
VIVELAND ${ }^{\mathrm{TM}}$, which includes many virtual reality games, in Taiwan [4]. The Institute of Transportation adopted an interactive mixed reality platform [5] to develop a tool to assist teachers to teach children to walk safely around their schools [6]. The Shihsanhang Museum of Archaeology invites visitors to use a virtual reality tool to explore an important Taiwanese underwater cultural asset, the British steamship SS Bokhara, which sank near Taiwan in 1982 [7].

\subsection{Digital Tour Guiding}

Brown in [8] examined earlier applications that demonstrated location - aware guiding by mobile devices, such as Cyberguide, which enabled a visitor to locate nearby bars, and GUIDE, which provided visitors with a means of personalizing information to suit their own interests and the environmental parameters. To increase the interactive elements, Bellotti in [9] built VeGame to operate on a cellular phone-mediated wireless connection between a pocket $\mathrm{PC}$ and the server, which communicated with the pocket $\mathrm{PC}$ via Bluetooth. VeGame was designed to enhance tourists' experience of art and history through a pleasant and challenging interaction with the heritage and people of Venice. When mobile devices became more widely used, Ballagas in [10] designed REXplorer, a device consisting of a Nokia mobile phone, a global positioning system (GPS) receiver, a camera, and a stretchable textile overlay with a zipper on the back that transformed a standard phone keypad into an 8-key game interface. Tourists could use REXplorer with gestures to interact with the significant buildings in Regensburg, Germany. Regarding indoor tour guiding, in addition to radio frequency identification (RFID) technology for positioning [11], Tsai in [12] proposed a position estimation method to design a location-aware tour guide system to be used with a personal digital assistant (PDA) by visitors to the National Palace Museum of Taiwan. As the user moved closer to items in the collection, the size of the materials became larger on the screen. Steiniger and Edwardes [13] indicated that location-based services (LBS) combined with GPS, geographic information systems (GIS), quick response $(\mathrm{QR})$ codes, mobile facilities and scene-point tour databases are an important future direction of such technology. Currently, advances in mobile technology make it feasible to use virtual and augmented reality technology for learning [14]. Doong in [15] investigated the chocolate-related knowledge learning effect of a game-based learning system developed with a crossplatform of LBS and mixed reality technologies. The virtual treasure-hunt game world was the real location of a chocolate factory that the participants had to find on Google Maps.

\subsection{Agile Development and Component-Based Software Engineering (CBSE)}

Developing game-based digital content is an expensive and risky activity. Using CBSE methods allows one to design digital content quickly by reusing existing functions and models to produce a system [16]. Folmer and Mehm's overview of developing games with components presents a reference architecture that outlines the relevant areas of reuse and signifies some of the problems with developing components unique to the domain of gaming [17, 18]. Elements characteristic of games (good competition, character development, improvement, inspiring and creative challenges, and activity) can easily be adapted to the needs arising from cultural settings. The results would be an increase in motivation and the development of positive relations with the cultural subject. Based on the spirit of the agile development method, Wu Junyue (2013) devised a set of development processes for mobile customer service that are best for the mobile service application [19]. Wu Junyue's development process $f$ reduces the output of unnecessary documents and uses repetitive development processes to shorten the development schedule. For these reasons, a challenge for the scientific community is to find new ways to visualize and disclose $3 \mathrm{D}$ digital contents to achieve better access to and communication of cultural heritage information [20]. Therefore, the purpose of this study is to determine how to develop digital guides rapidly and make them suitable for more kinds of handheld equipment.

\subsection{D Virtual Game-based Environment}

Effective learning is situated, active, and problem-based and requires immediate feedback [21]. Gaming elements provide an instructional environment with stimulation and learning motivation [22, 23]. A well-designed virtual educational game provides complex holistic problem-based environments, making it possible to develop situated understanding [24] and thus supporting effective learning. Virtual game-based environment designs follow the rules of game design. Nevertheless, the purpose is not only to entertain [25] but also to use the characteristics of video and computer games to create attractive and immersive learning experiences to achieve specific learning objectives [26]. In addition to the four important features (gameplay, feedback, interface, and challenge) of a good game [25], the design of a game-based learning system must further consider the realism of the game, the opportunities to explore and obtain new information, and the meaning of learning controls [26]

\subsection{Agile Development and Digital Content Development}

The effectiveness of the selection of the game template components and the game design is also the most thought-out part of the process of implementation. For example, Teng Feng Fishball Museum (TFFM) at Tamsui is a food tourism location where the TFFM combines the history and cultural characteristics of the Tamsui. The TFFM is focused on individuals or family members and is supported by a rich history and cultural knowledge. The TFFM can present more profound educational material and understanding with 3D VR game types. However, this kind of innovative food museum can also present a variety of innovative food products by focusing on entertaining 2D game templates. Both digital guides focus on increasing the pleasure of the user experience, allowing the user to learn more about tourist attractions, or increasing tourists' pleasure in traveling on their own. Digital guides also meet educational needs and draw visitors into visiting the museum.

\section{Methods}

\subsection{The Game-based Tourism Information Service System (GTISS)}

The Game-based Tourism Information Service System (GTISS) was developed for the purpose of breaking geographical and temporal restrictions. 3D virtual and game-based tourist attractions were created using Unity software. Three major elements are including in the GTISS: itinerary planner, games and 
virtual reality design, and cultural tourism features. The concept of CBSE was adopted in the development of the GTISS by agile methods.

The GTISS is designed to break geographical and temporal restrictions by creating $3 \mathrm{D}$ virtual and game-based tourist attractions using Unity software. There are three major elements in the GTISS, including an itinerary planner, virtual game-based design, and cultural tourism features. The concept of CBSE was adopted in the development of the GTISS by agile methods. Employing CBSE in the design of a tourism information platform expedites the process, that is, multimedia components (e.g., game plans, 2D icons and pictures, music, sound effects, 3D models, and programs) in a previously created database can be used and reused for various projects, which lowers the threshold for developing a tourism information platform and adds value to existing tourism materials. Cultural tourism is often full of story-like elements; thus, to enhance the attractiveness of a cultural tourism information platform, it is necessary to improve its storytelling ability and incorporate the LBS and game elements into the platform [27]. Web3D, GIS, GPS, and Unity3D VR software were used in the present study. The goal of CBSE is to establish a digital content development platform consisting of reusable components; this platform can shorten the time for developing a project. Drawing on the concept of CBSE, the multimedia component database allows developers who do not have enough game development background to design the content of the platform easily. Finally, all the components in the database were created to be compatible with the Unity 3D engine.

To develop the GTISS, first, information content about tourist attractions was collected. Then, based on the features and characteristics of each tourist attraction and the corresponding game plans, appropriate components in the multimedia component database were searched to design a game that presents the information about each tourist attraction. LBS integrated the QR code to enhance the contextualized interaction. Tiered with levels of difficulty, it features requirements, such as time limits and penalties, that add excitement and competition to the game. The accomplishment of finding a destination involves answering questions or solving problems in some well-known scenic spots. Moreover, for users, the platform provides travel guides to the tourist attractions by showing available public transport through dynamic maps and consecutive pictures of real street views. In addition, by using Google Maps application program interfaces (APIs), the platform shows the GPS locations of the tourist attractions on Google Maps, which is familiar to many users.

\subsection{Agile Development and Digital Content Development}

A number of tourist attractions that the government actively promotes were selected for information collection. Each digital guide for the tourist attractions provides public transport information integrated into the digital map to promote a Low Carbon Tour. Applying the appropriate game plan for an attraction's information confirms that the characteristics of the attraction's content are sufficient for the resources required for the game plan. For example, if there is not enough information about the attraction, then the use of the real tour will lead to digital guide content that is not attractive. Finally, we applied the modular component and game design principles of the plan to archive the digital guides. With the Unity $3 \mathrm{D}$ engine, the completed digital guide can be built into different carrier formats (such as html, apk, and exe). The process of component-based agile game and digital content development used by this study is shown in Figure 1 .

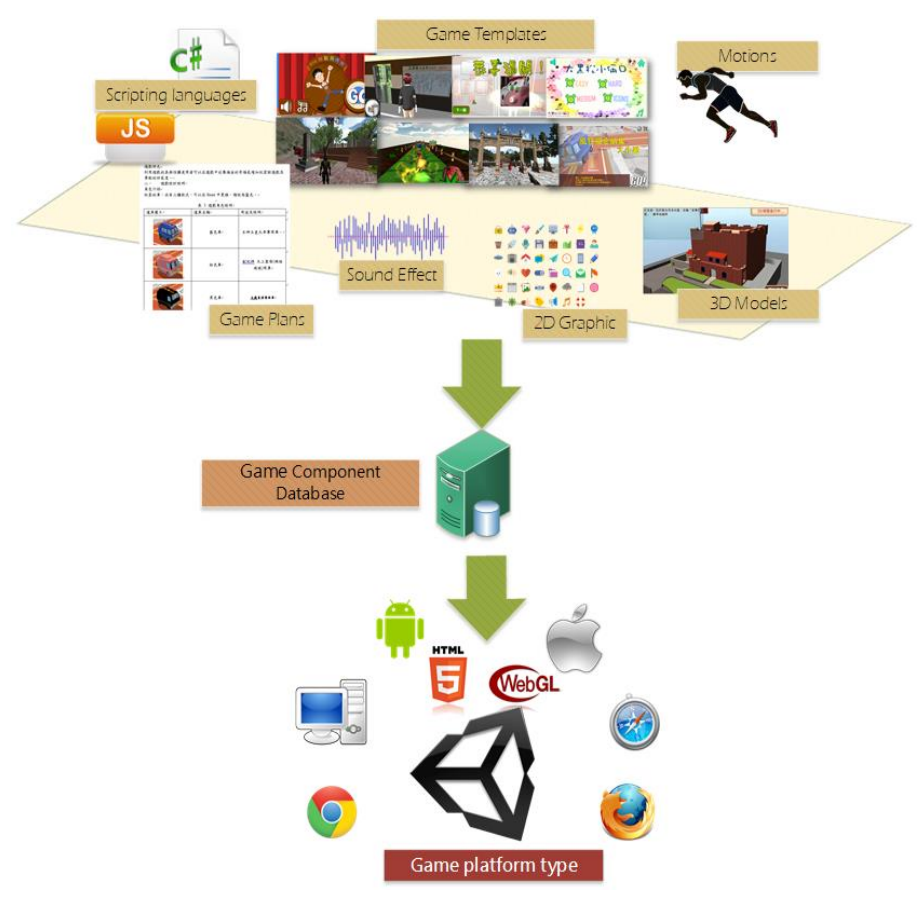

Figure 1 The process of use agile design method to make digital content

The effectiveness of the selection of the game template components and the game design is also the most thought-out part of the process of implementation. For example, Teng Feng Fishball Museum (TFFM) at Tamsui is a food tourism location where the TFFM combines the history and cultural characteristics of the Tamsui. The TFFM is focused on individuals or family members and is supported by a rich history and cultural knowledge. The TFFM can present more profound educational material and understanding with 3D VR game types. However, this kind of innovative food museum can also present a variety of innovative food products by focusing on entertaining 2D game templates. Both digital guides focus on increasing the pleasure of the user experience, allowing the user to learn more about tourist attractions, or increasing tourists' pleasure in traveling on their own. Digital guides also meet educational needs and draw visitors into visiting the museum.

To rapidly develop a game-based digital guide, componentbased templates were used to develop a digital guide of tourist attractions. The construction of the modular component database replaced the homemade or commercially available development resource modularization database. Seven component databases were established and used to develop a game-based digital guide that can be viewed on webpages or handheld devices. The component databases are shown in Table 1. A motion database and a game template database were recently completed. After developing several games, the humanoid character can be used in a cross-game motion template. We expanded our motion database 
by using $\mathrm{x}$-box to scan simple motions that the game needed and binding the motion to the characters.

Table 1: Component-Database of this study

\begin{tabular}{|c|c|}
\hline Database Name & Content \\
\hline 3D Model & $\begin{array}{l}\text { The 3D model library contains models such as } \\
\text { character, buildings, and objects that built from a } \\
\text { variety of modeling software, such as 3D Max, } \\
\text { Maya, and SketchUp. All models are finally } \\
\text { imported in the development engine with .fbx } \\
\text { format }\end{array}$ \\
\hline 2D Graphic & $\begin{array}{l}\text { This database contains illustrations for animations } \\
\text { and interface designs such as picture or icon. The } \\
\text { 2D material in database licensed under creative } \\
\text { commons. Some of these art files may } \\
\text { contain .jpg, .png, and so on in different file } \\
\text { formats. }\end{array}$ \\
\hline Scripting language & $\begin{array}{l}\text { This study aimed at scripting and sorting all kinds } \\
\text { of shareable functions in game templates. For } \\
\text { example, the function of these feet for the game } \\
\text { interface to return and explain the function, the } \\
\text { game time count/pause/stop, props configuration, } \\
\text { character action control. All scripts has been } \\
\text { documentation for re-use by non-game } \\
\text { developers. }\end{array}$ \\
\hline Game Plan & $\begin{array}{l}\text { The game template of this study will be self- } \\
\text { development and collect from web resource } \\
\text { database. We write planning documents for each } \\
\text { free or paid game template for non-game } \\
\text { developer to use. }\end{array}$ \\
\hline Sound Effect & $\begin{array}{l}\text { Collect, organize and use the sound studio or } \\
\text { online recording software produced by the various } \\
\text { sound effects database. All content licensed under } \\
\text { creative commons, and contains include .mp } 3 \\
\text { or .wmv and other file formats of sound. }\end{array}$ \\
\hline Motion & $\begin{array}{l}\text { In addition to collecting free motion files available } \\
\text { on the network, find out how to organize the } \\
\text { motion files from ready-made game templates into } \\
\text { other game templates. This study also used X-Box } \\
\text { for Motion capture to record the movements of } \\
\text { real people and mapping the movements onto the } \\
\text { CG character. }\end{array}$ \\
\hline Game Template & $\begin{array}{l}\text { By implement the game plan into real game, there } \\
\text { are eight game template had been build. There are } \\
\text { nine game template in our database. }\end{array}$ \\
\hline
\end{tabular}

In addition to the integration of models, animations and sound effects in the game development process, the development of game script language is also very important. However, the number of script resources that can be used directly in the game is less than the number of models or sound effects. As shown in Figure 2, if building a script language database can be organized, then the time that programmer used to rewrite the code can be saved. The developer simply confirms the required functionality, finds the appropriate script resource in the database, and imports it into the Unity game engine. Fine-tuning allows game developers to quickly develop game features and add new script into the script database.

\subsection{0-Degree Virtual Tour Guide}

To increase the sense of participation, an attempt was made to imitate the indoor and outdoor feeling of the attractions that visitors would experience. Some of the attractions are not well defined by their location or are connected to a factory, and the user cannot find the entry.

This study uses Google Street View's screenshots to build a 360degree VR scene. The application of this 360-degree scene setting in this platform mainly provides an indication of the user's arrival status at the attraction. Using the 360-degree circular guide at the entrance increases the user's understanding of the geographical location of the scenery. The design of this scene can be applied to the design of future AR scenes. The scene of this study is based on the use of Google Street View and real indoor photos made during field trips to build outdoor and indoor scenes. In the future, the user may use the camera lens of the mobile device as a source, and the digital guide instructs the user to provide information or tips based on all the current locations.

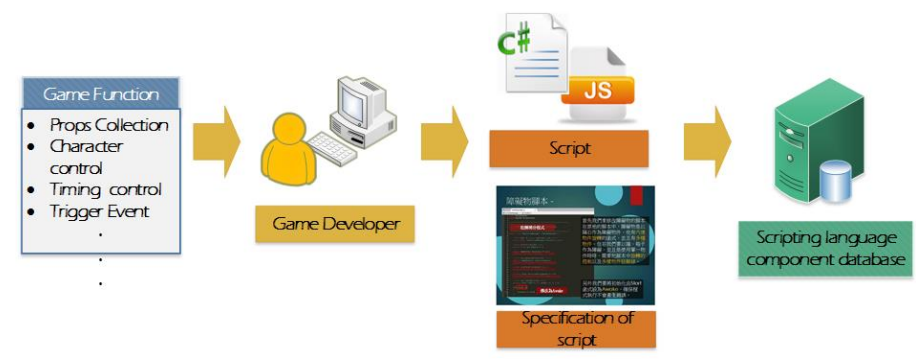

Figure 2 The process of build Scripting language component database

\section{Results}

\subsection{Game-based Component Database}

This study built seven component databases, as described in Table 1. Figure 3, Figure 4 and Table 2 are the samples of the 3D models, different motions and sound effects collected in this study in the present component databases. Regarding the 3D character models, for example, there are currently ten 3D character models in the database. As shown in Figure 3, the same character can be used in different games quickly with various motions. The movement of running includes running forward, turning left, and turning right. The motions of touching the head and waiting are bound to form the other motion. Some motion files for men and female are different. In the different games shown in Figure 3, it is possible not only to reuse the $3 \mathrm{D}$ character model in the game template but also to use 3D models of terrain and trees. User interface (UI) templates in the 2D graphic database can be created for different attractions easily, quickly and repeatedly. As shown in Figure 4(a), the same UI template was used in the National Dr. Sun Yat-sen Memorial Hall and the Vigor Kobo Dream Museum. Through a color change, the same UI component can quickly adapt to each game template. Similarly, by using consistent icons, the user can understand the meaning of the graphic on the screen. As shown in Figure 4 (b), the icons on the screen are the indispensable elements that guide the user to operate the icon related functions. During the preliminary stage of design, it took about a month to accomplish the construction of a scenic spot whereas only five working days were needed in the later stage for the creation and modification of an attraction, which is the most time-consuming of the entire project. 


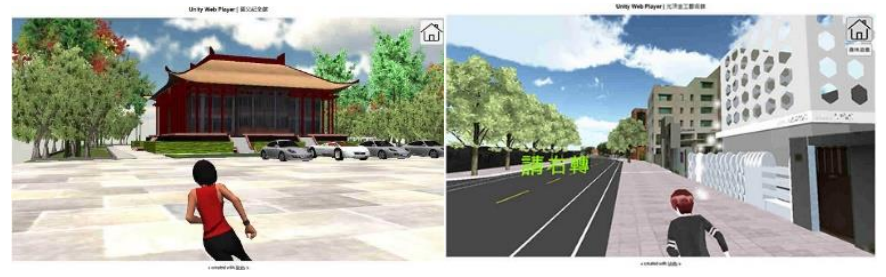

(a) Turn-left running motion on female (b) Turn-left running motion on man

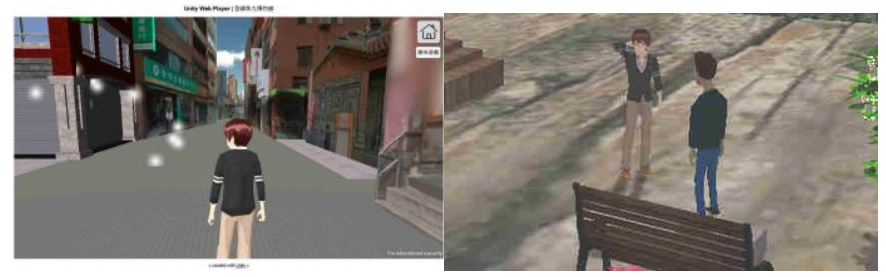

(c) The waiting motion (d) Touch head motion and two character

Figure 3 The 3D character models and motions in different game

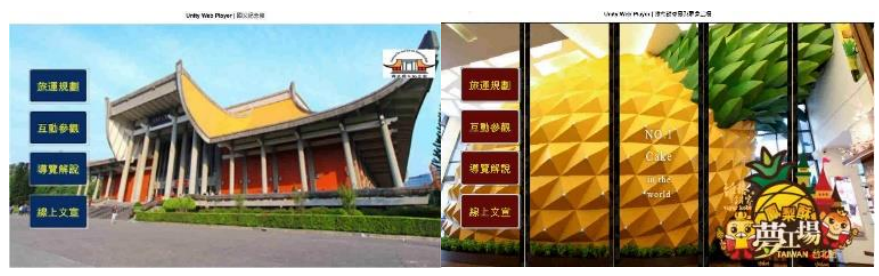

(a) The UI template used by two attraction

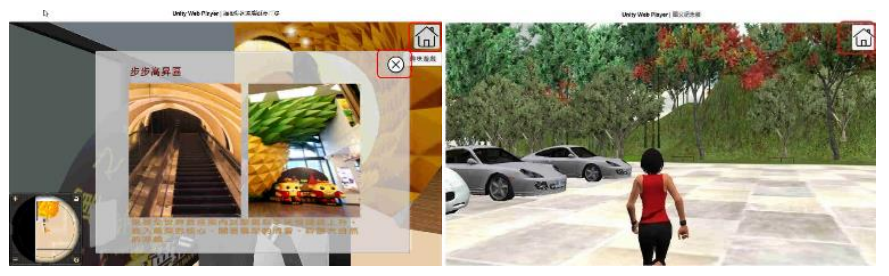

(b) The icon used by different game

Figure 4 The 2D UI template and close icon be reuse in our project for saving the time of development

\subsection{The Tourism Digital Guiding Platform (TDGP)}

In the present study, the GTISS was designed and shown as in Figure 5. All attraction locations were labeled in Google Maps and categorized into six types: food, shopping, heritage, transportation, education, and entertainment. User-friendly interfaces enable visitors to find interesting locations easily. Fifteen cultural locations were chosen and designed in the TDGP. Figure 6 shows the template for planning the route to the destination (e.g., from Taipei Main Station to the Taiwan Socks Museum). Users can choose to board at the mass rapid transport (MRT) station. Then, according to the routing algorithm, the user can achieve the minimum number of transfers or the shortest distance calculated from the number of stops. Both the interactive display technology of the LBS geographic location and the 3D VR/AR are important trends in the digital content industry.

The interactive traffic information guideline was provided by the destination websites. Combined with the street/attractions and
Table 2 Component-Database of this study

\begin{tabular}{ll}
\hline Attractions & BGM \\
\hline Anping Castle & Path to Follow.mp3 \\
Republic of Chocolate & The_Messenger.mp3 \\
National Dr. Sun Yat-sen Memorial Hall & Clouds.mp3 \\
Longshan Temple & Clouds.mp3 \\
Taiwan's Socks Museum & On the Bach.mp3 \\
W \& W Museum of Jewelry & On the Bach.mp3 \\
Vigor Kobo Dream Museum & Festival.mp3 \\
National Palace Museum & The_Engagement.mp3 \\
Lanyang Museum & Retreat.mp3 \\
Dali Tian Gong Temple & Succotash.mp3 \\
Kuo Yuan Ye Museum of Cake and & Reasons_to_Smile.mp3 \\
Pastry & \\
Taiwan Nougat Creativity Museum & Morning Walk.mp3 \\
KONG YEN Yi Shou Dou Cultural & Microchip.mp3 \\
Museum & Keith.mp3 \\
Shu Shin Bou Wagashi Museum & Morning Walk.mp3 \\
\hline
\end{tabular}

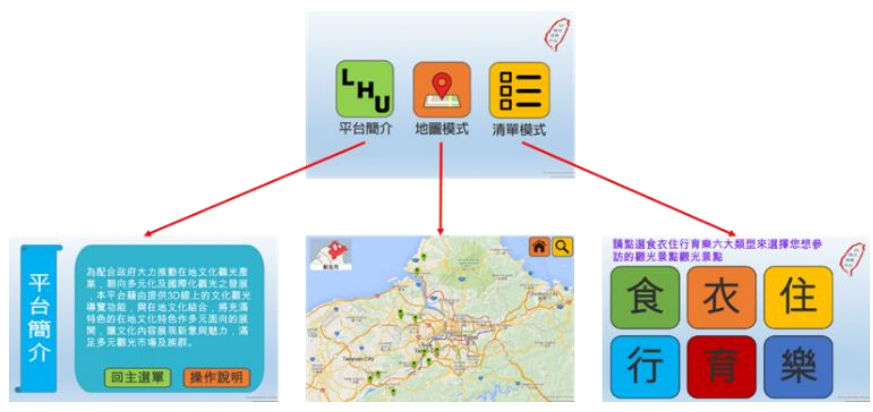

Figure 5 The tour platform use Google Maps API to presentation
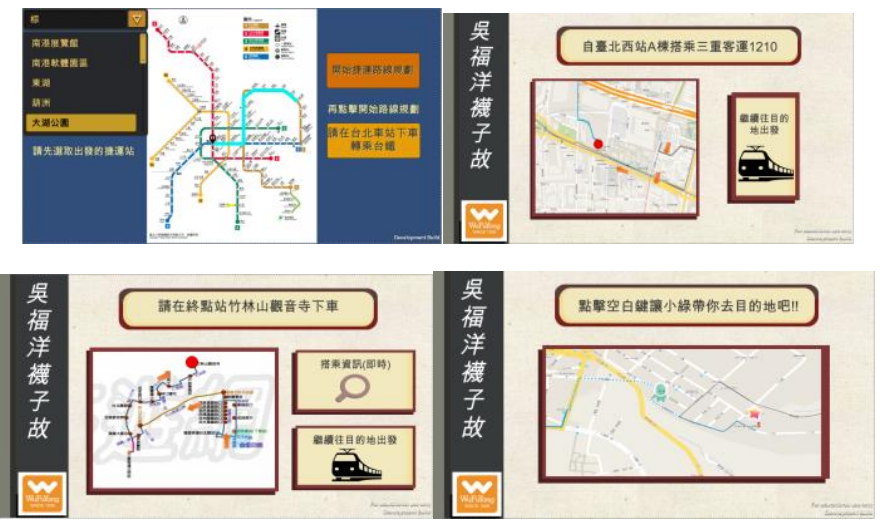

Figure 6 Dynamic route planning to Taiwan's Socks Museum( 
outdoor/indoor navigation technology of an attraction's features, users can have an in-depth understanding of the tourist information and be impressed by the digital tour guides.

The completion of each level involves answering questions and solving problems. Answers to the questions can only be found by asking locals questions, exploring the surroundings, or using certain services specific to a location. At the outset, the QR code of a zone must be photographed, and when all the questions in that zone are answered or when the problems are solved, the user can then advance to the next level of his/her choice.

Figure 6 shows useful travel guides included in the tourist attractions with available public transport route information through dynamic maps. By using the 360-degree circular guide, consecutive pictures of real street views can be provided to increase the visualization and understanding of those locations (shown in Figure 7). The platform shows the GPS locations of the tourist attractions on Google Maps, and more LBS information can be added to the system.

The 2D/3D game-based learning content of fifteen attractions are shown in Figure 8. These are famous attractions in Taiwan and are promoted by the Taiwan Tourism Bureau. The development of a digital tour guide is mainly based on 3D game types. However, the architecture is the main part of building the 3D models of the attractions, and it requires more time and work to adjust during the development process. To attain the purpose of the agile development of the new digital guide, this study also built some interesting 2D game templates for our database to save time and reduce the needed process in developing digital tour guides, as shown in Figure 8.

\subsection{D AR / VR Game-based Tourism Service}

Seven databases were used in designing the 15 attractions for the effective and efficient development of the game. Table 3 shows the number of 2D graphics with the game templates applied in the 15 attractions. Figure 9 shows several 2D graphics used in the game templates. Most reusable images are icon-type graphics, which can change color, size, and text. In addition, each game has background music, which was chosen from the background music (BGM) database based on rhythm and types. Table 4 shows all the music applied in the game templates for the study.

To create a 3D VR game template, a goal-oriented puzzle or treasure hunt was created by interacting with the object in the scene (Table 5 ). The Unity3D game engine was used to build indoor and outside VR panoramas of attractions in this tourism platform. Google street view was used for outdoor scenes, and 3D models with real indoor photos of the museums were created in the present study. Through the implementation of an online VR tour, users can have pleasure and further understand the details of the attractions.

There are nine kinds of game templates built in the component modules. By using these component modules, a digital guide with $3 \mathrm{D}$ VR real scenes were provided to visitors for touring both the indoor and outdoor attractions (as is shown in Figure 10). This study organized the game-based component templates and created vivid scenarios of scene tours for visitors to enhance the interaction with the digital guide. Nine kinds of game templates with three game types are shown in Table 5.

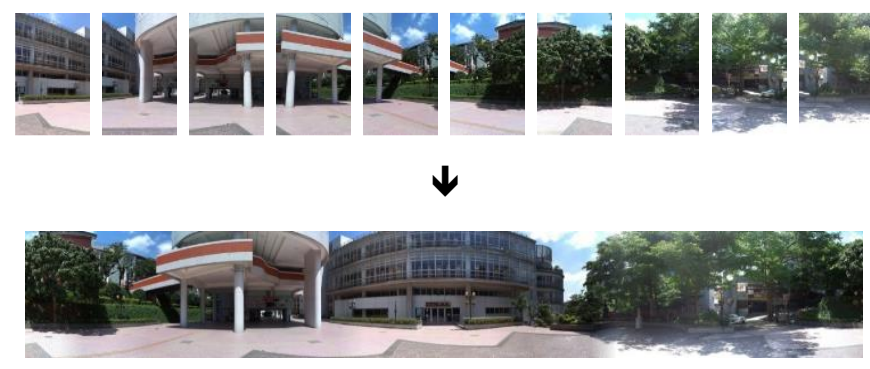

Figure 7 This study use Google Street View's screenshots to build up a 360degree VR scene

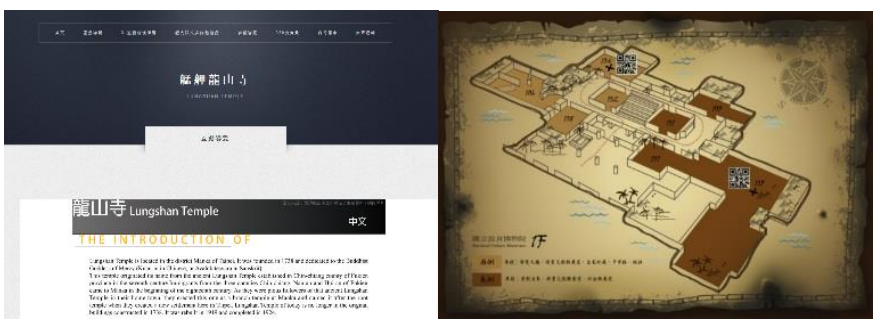

(a) Culture Content Introduction

(b) 2D Layout link with LBS Service

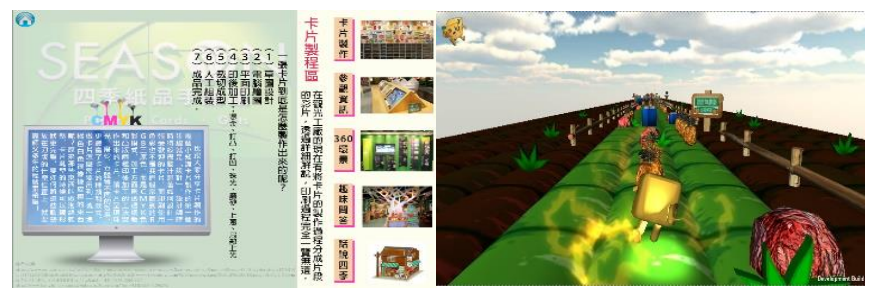

(c) 2D Multimedia Learning Game

(d) 3D Porger Game

Figure 8 The Cultural Tourism Digital Guiding Platform

Table 3 Number of Sound used by 15 Attractions with Game type

\begin{tabular}{|c|c|c|c|c|}
\hline \multirow{2}{*}{ Sound } & \multicolumn{3}{|c|}{ Game Type } & \multirow{2}{*}{ Total } \\
\hline & $2 \mathrm{D}$ & $3 \mathrm{D}$ & $3 \mathrm{D} V \mathrm{VR}$ & \\
\hline BGM & 5 & 5 & 5 & 15 \\
\hline Bird & & 1 & & 1 \\
\hline Cannon sound & & & 1 & 1 \\
\hline Cue Tone -Button Click & 4 & & & 4 \\
\hline Cue Tone -Notice & & 1 & 4 & 5 \\
\hline Cue Tone -Pass & 1 & 1 & & 2 \\
\hline Cue Tone -Pick up Item & 1 & 2 & & 3 \\
\hline Cue Tone -Wrong & 4 & 1 & 4 & 9 \\
\hline Cue Tone-Car Crash & & 1 & & 1 \\
\hline $\begin{array}{l}\text { Cue Tone-Loss Health } \\
\text { points }\end{array}$ & & 2 & & 2 \\
\hline Cue Tone-Miss Hit & 1 & & & 1 \\
\hline Cue Tone-Most Time Up & 4 & & & 4 \\
\hline Cue Tone-Notice & & 1 & & 1 \\
\hline Cue Tone-Right & 4 & 1 & 4 & 9 \\
\hline Cue Tone-Time Up & 4 & & & 4 \\
\hline Explosion & & 1 & & 1 \\
\hline Mining sound & & & 1 & 1 \\
\hline Racing Sound & & 1 & & 1 \\
\hline Shooting sound & 1 & 1 & & 2 \\
\hline Train arrive & & 1 & & 1 \\
\hline Typing Effect & & 1 & & 1 \\
\hline Water of fountain & & 1 & & 1 \\
\hline Wheel Rolling Sound & 1 & & & 1 \\
\hline Wind sound & & & 1 & 1 \\
\hline Total & 30 & 22 & 20 & 72 \\
\hline
\end{tabular}


W.H. Huang et al. / Advances in Science, Technology and Engineering Systems Journal Vol. 3, No. 1, 451-459 (2018)

Table 4 Number of Attractions with Game template and Game type

\begin{tabular}{|c|c|c|c|c|}
\hline \multirow{2}{*}{ Game Template } & \multicolumn{3}{|c|}{ Game Type } & \multirow{2}{*}{$\begin{array}{l}\text { Number of } \\
\text { Attractions }\end{array}$} \\
\hline & $2 \mathrm{D}$ & $3 \mathrm{D}$ & $3 \mathrm{D} V \mathrm{R}$ & \\
\hline Book Template & \multicolumn{3}{|c|}{1} & 1 \\
\hline t Wheel Game Template & \multicolumn{3}{|c|}{1} & 1 \\
\hline t Personal Shooting Game & \multicolumn{3}{|c|}{1} & 1 \\
\hline den Object Game Template & \multicolumn{3}{|l|}{2} & 2 \\
\hline stery Jigsaw Game Template & \multicolumn{3}{|l|}{2} & 2 \\
\hline kour games Template & \multicolumn{3}{|c|}{1} & 1 \\
\hline zle Game Template & \multicolumn{3}{|r|}{2} & 2 \\
\hline ing Game Template & \multicolumn{3}{|c|}{1} & 1 \\
\hline asure hunt game Template & & 1 & 3 & 4 \\
\hline al & 5 & 5 & 5 & 15 \\
\hline
\end{tabular}

Table 5 Number of 2D Graphic used by 15 Attractions with Game type

\begin{tabular}{|c|c|c|c|c|c|c|c|c|c|c|c|c|}
\hline \multirow{2}{*}{ 2D Graphic } & \multicolumn{3}{|c|}{$2 \mathrm{D}$} & \multirow{2}{*}{$\begin{array}{l}2 \mathrm{D} \\
- \text { Total }\end{array}$} & & \multicolumn{4}{|c|}{$3 \mathrm{D}$} & \multicolumn{2}{|c|}{ 3D } & \multirow{2}{*}{$\begin{array}{l}\text { 3D } \\
\text { VR } \\
\mathrm{J} .\end{array}$} \\
\hline & A. & B. & C. & & D. & E. & F. & G. & $\mathrm{H}$. & I. & Total & \\
\hline Entry Graphic & 1 & & 2 & 3 & & 1 & & & & & 1 & \\
\hline Exit Icon & 1 & 2 & 2 & 5 & & & 1 & 1 & 1 & & 3 & \\
\hline Game Over & 1 & 2 & 2 & 5 & & & 1 & 1 & 1 & & 3 & \\
\hline Home Icon & 1 & 2 & 2 & 5 & & 1 & & & 1 & 1 & 3 & 2 \\
\hline Level-Hard & & 2 & & 2 & & & & & & & & \\
\hline Level-Midium & & 2 & & 2 & & & & & & & & \\
\hline Level-Simple & & 2 & & 2 & & & & & & & & \\
\hline Man-Waiter & 1 & & & 1 & & & & & & & & \\
\hline Next icon & & & 2 & 2 & & & & & & & & \\
\hline Next-Page & & & & & & 1 & & & & & 1 & \\
\hline Pause & & & & & & & & 1 & & & 1 & \\
\hline Pre-Page & & & & & & 1 & & & & & 1 & \\
\hline Replay Icon & 1 & 2 & 2 & 5 & & & 1 & 1 & 1 & & 3 & \\
\hline Right & & & & & & 1 & & & & 1 & 2 & 2 \\
\hline Setting Icon & 1 & 2 & & 3 & & & & & 1 & & 1 & \\
\hline Store & & & & & & & & & 1 & & 1 & \\
\hline Success & & & & & & & & 1 & & 1 & 2 & 2 \\
\hline \multicolumn{13}{|l|}{ Treasure Map } \\
\hline Try Again & & & & & & & & & & 1 & 1 & \\
\hline $\begin{array}{c}\text { UI } \\
\text { Background }\end{array}$ & 1 & 2 & 2 & 5 & & & & & & & & \\
\hline Wrong & & & & & & 1 & & & & & 1 & 2 \\
\hline 總計 & 8 & $\begin{array}{l}1 \\
8\end{array}$ & $\begin{array}{l}1 \\
4\end{array}$ & 40 & & 6 & 3 & 5 & 6 & 4 & 24 & 8 \\
\hline
\end{tabular}

Notice the Symbol of Game Template
A. Dart Wheel Game Template
B. Hidden Object Game Template
C. Mystery Jigsaw Game Template
D. 3D Book Templete
E. First Personal Shooting Game
F. Parkour games Template
G. Racing Game Template
H. Treasure hunt game Template
I. Puzzle Game Template
J. Treasure hunt game Template

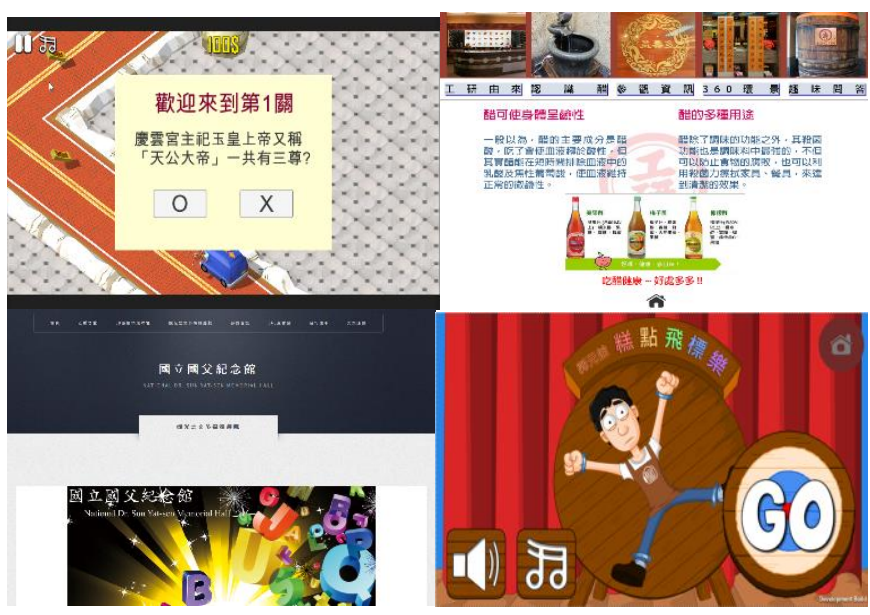

Figure 9 The 2D Gameful Design Digital Guide of this research

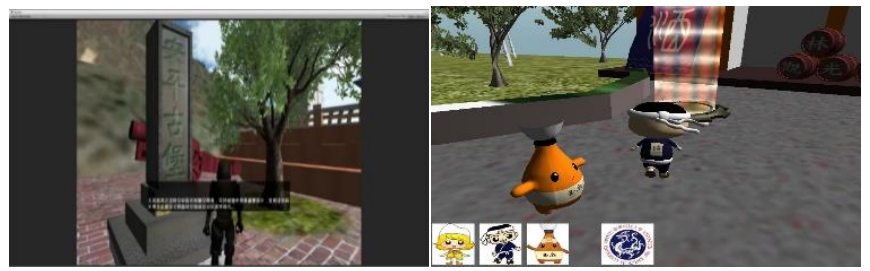

(a) The 3D Geometry-base Model VR Digital Guide

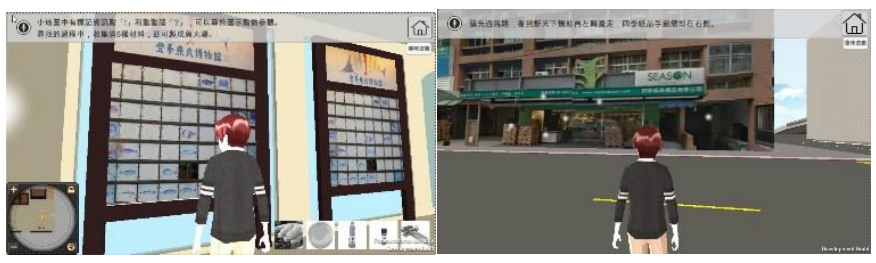

(b) The Image-base Background with 3D Geometry-base Model VR Digital Guide

Figure 10 The Digital Guide of this research

During the 2D game development period, a navigation e-book was also built to be merged with the 3D model. The design of the navigation e-book has been improved from the original 2D material to the 3D model library by adding a UI interface for a more interesting and clear introduction. To upgrade the function of the navigation e-book content, we incorporated $2 \mathrm{D}$ text descriptions and dynamic 3D guidance to enhance the entire navigation e-book'tals readability. This navigation e-book is released on a Unity platform. There is a PC version, a web format, and an .apk format for other handheld devices.

Animations and interactive elements were added to this navigation e-book to increase the interactivity between the digital content and the users. Using Lan Yang Museum's 3D navigation e-book as an example, on the floor map page, by clicking on the 3D text on the left and the red indicator on the right side of the page, it will move to the floor on the map (Figure 11(a)). In the traffic guide page, the 3D models of moving trains and buses, as shown in Figure 11(b), were also added to improve the appeal of the e-book as well as the enjoyment of the visitors.

To further expand our VR games into AR games. Three museums' logo images were chosen as the AR image-based 457 


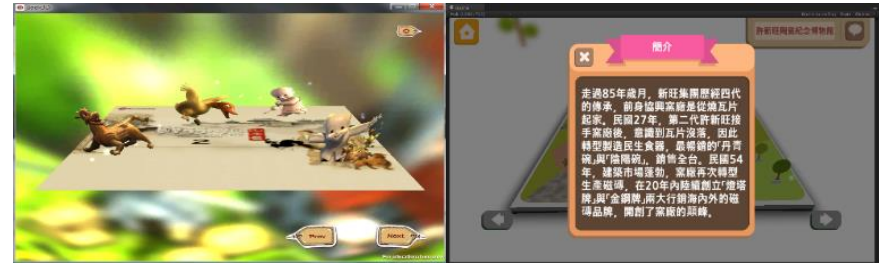

(a) PC version 2D e-book model (b) $2 \mathrm{D}$ e-book with UI

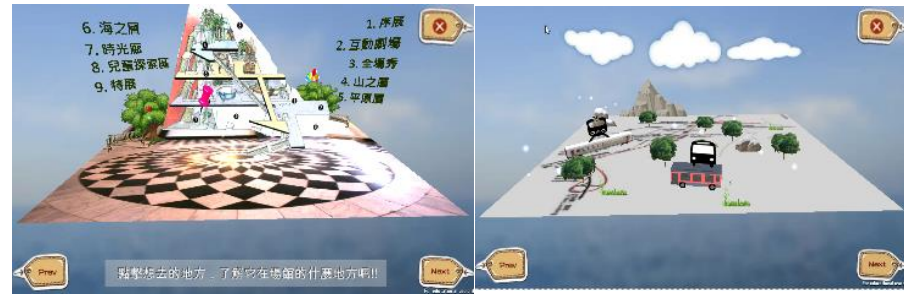

(c) E-book with 2D map and 3D words

(d) E-book With dynamic 3D model

(Bus and Train)

Figure 11 The screenshots of Lan Yang Museum's navigation e-book (apk)

identification, which can generate four identifications supported by the Unity software: single picture identification, cuboid identification, cylinder identification and 3D object identification. When the AR glass lens captures the correct image object, other instructions from the weblink or hyperlink to the museum website are triggered (as shown in Figure 12).

\section{Discussion}

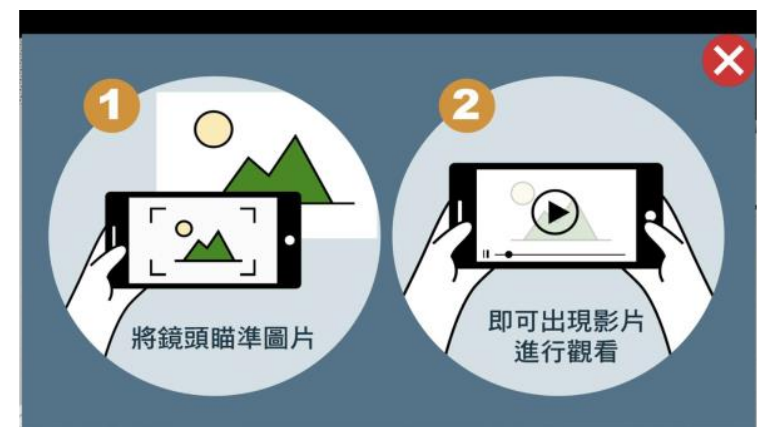

(a) The screenshot of mobile device that hint user how to use AR

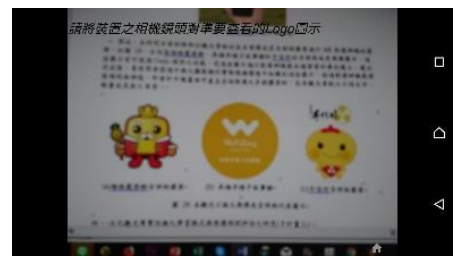

(b) The logo photo capture by mobile device

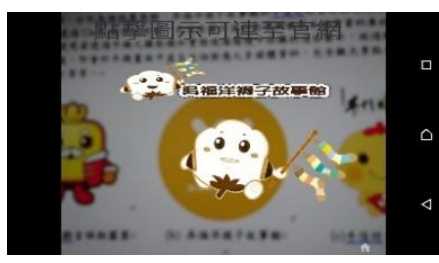

(c) Show the Mascot's Animation
Figure 12 Screenshot of AR identification in this research

It is important to design and develop game-based digital tour guides using agile development and component databases in the future. Game-based digital guide learning easily increases not only the entertainment effect but also the understanding and recollection of the cultural attractions. However, to accomplish this complex work (drawing the 3D model, writing the coding, producing the music, etc.) requires a long development process. Developers with experience in game design need at least a month to finish a game project without using a component database. Using the game-based component database, intern students with no experience in game development were trained to complete the first digital game guide within two weeks. After completing the first project, four intern students found new attractions and used game templates to develop new game-based digital guides on their own. The intern students can not only develop independently but also shorten the design period to within a week. In the future, nongame professional tour staff can complete their own interesting digital tour guides easily and quickly.

After the platform is established, the attention of younger users can be captured by measuring the accuracy of the questions that users answer before and after using the platform. If the digital tour guide of this platform is sufficient to attract users to browse, read and memorize the content, the accuracy of the answers in post-test results should be improved. There were 477 student participants. Their ages ranged from 18 to 22 years old, and the number of female students (338 or $70.9 \%$ ) was higher than the number of male students (139 or $29.1 \%$ ). This study used a pre-test and posttest on knowledge content design issues for the platform attractions. The pre-and post test aimed to examine whether students enhanced their understanding of the attractions and the online travel planning. The items include an itinerary planner, games and virtual reality design, cultural features of the attractions, and Tourism English. Students did the pre-test before the experiment and the post test after it. The experiment lasted for one hour. The purpose of the system design was explained and the operational functions were demonstrated before the experiment. Pre- and post-tests were created based on the content of the system to examine student learning on the platform. As shown in Figure 13 (a), both males and females increased their correct answer rate after using the platform. Figure 13 (b) shows the pre- and post-test correct answer rates for question 3-1 in the questionnaire. The post-test correct answer rates for both males and females were $10 \%$ or higher than the pre-test. These results are sufficient to initially demonstrate the validity of the digital tourism content on the platform established by this study. The game-based digital tour guides with locality-specific information and culture in mind can make not only real hands-on experiences but also experiences that are memorable and worth sharing.

\section{Conflict of Interest}
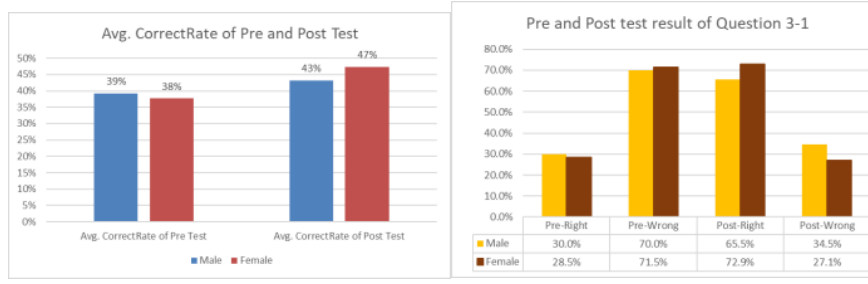

$\begin{array}{ll}\text { (a) Avg. CorrectRate of Pre and post test } & \text { (b) Pre and Post test result of Question 3-1 }\end{array}$

Figure 13 Two result of pre and post test

The authors declare no conflict of interest.

\section{Acknowledgment}

This research is supported by the Ministry of Science and Technology, Taiwan, R.O.C. under Grant no. MOST 104-2632H-262 -001 -MY2. 
This paper was originally published in the 2017 IEEE International Conference on Applied System Innovation(ICASI), May 13-17, 2017, Hotel Emisia, Sapporo, Japan.

\section{References}

[1] Courtney Tucci. Statistics and Facts on Museums. Retrieved from https://www.statista.com/topics/1509/museums/ (2015).

[2] [2] Ministry of Culture (2015). Taiwan Cultural Creative Industries Annual Report 2016 (in Chinese). Ministry of Culture.

[3] [3] Institute for Information Industry (2016). 2015 Digital Content Industry in Taiwan (in Chinese). Ministry of Economic Affairs, Industrial Development Bureau.

[4] [4] HTC. VIVELAND (https://www.vive.com/tw/viveland/).

[5] [5] Ji-Liang Doong Ching-Huei Lai, Kai-Hsiang Chuang, Chun-Chia Hsu (2015, Jul). The Development of Location-based Mobile Augmented Reality (LoMAR). The 3rd International Conference on Hospitality, Leisure, Sports, and Tourism. July 23-24, 2015, Waseda University, Tokyo, Japan .

[6] [6] Chun-Chia Hsu, Chih-Yung Lin, Yu-Li Chen, Wei-Shin Huang, KaiHsiang Chuang, Huei-Ming Chiao in (2017) Tools development of investigating roads and using roads for pedestrians and bicyclists $(1 / 3)-$ Applications of road safety audit (in Chinese). Institute of Transportation, Department of Transportation and Communications.

[7] [7] The Shihsanhang Museum of Archaeology. Virtual reality exploring the S. S. Bokhara (http://www.sshm.ntpc.gov.tw).

[8] [8] Brown, Elizabeth; Brner, Dirk; Sharples, Mike; Glahn, Christian; de Jong, Tim and Specht, Marcus (2010). Location-based and contextual mobile learning. A STELLAR Small-Scale Study. STELLAR European Network of Excellence in TEL (EU).

[9] Bellotti, F., Berta, R., De Gloria, A., Ferretti, E., \& Margarone, M. (2003). VeGame: exploring art and history in Venice. Computer 36(9), 48-55

[10] Ballagas, R., Kuntze, A. and Walz, S. P. Gaming Tourism: Lessons from Evaluating REXplorer - a Pervasive Game for Tourists. In: J. Indulska in (Eds.): Pervasive 2008, LNCS 5013, pp. 244-261, 2008. Springer.

[11] Wang, Y., Yang, D., Liu, S., Wang, R. and Meng, X. A RFID \& Handheld Device-Based Museum Guide System. in Proceedings of the International Conference on Pervasive Computing and Applications (ICPCA), 2007, pp.308-313.

[12] Tsai C Y, Chou S Y, Lin S W. Location-aware tour guide systems in museum. Scientific Research and Essays, 2010, 5(8): 714-720.

[13] Steiniger, S., Neun, M., \& Edwardes, A. (2006). Foundations of Location Based Services: University of Zurich.

[14] Specht, M., Ternier, S., \& Greller, W. (2011). Dimensions of mobile augmented reality for learning: a first inventory. Journal of the Research Center for Educational Technology, 7(1), 117-127.

[15] Ji-Liang Doong, Ching-Huei Lai, Kai-Hsiang Chuang, Chun-Chia Hsu, Learning Effects of Location Based Mixed Reality Game: A Pilot Study, Procedia Manufacturing, Volume 3, 2015, Pages 1603-1607.World Tourism Organization. (2017).UNWTO Tourism Highlights: 2017 Edition - UNWTO Elibrary

[16] Bei-lin Lin, "On the rebuild-of the XBRL Demosite by using componentbased design.", Master Thesis, National Central University, 2011

[17] Folmer, E., Component based game development : A solution to escalating costs and expanding deadlines. CBSE'07 Proceedings of the 10th international conference on Component-Based Software Engineering( pp. 66-73) (ISBN: 978-3-540-73550-2) (2007)

[18] Florian Mehm, Stefan Gobel, Ralf Steinmetz. Introducing component-based templates into a game authoring tool. In Dimitris Gouscos and Michalis Meimaria (ed.) 5th European Conference on Games Based Learning (pp. 395403)., Reading, UK: Academic Conferences Limited. (2011)

[19] JYUN-YUE WU, "Applying Agile Method to Building Mobile Application Software and Services", Master thesis, Shih Hsin University,2013

[20] Poria Y, Bulter R, Airey D. The core of heritage tourism. Annals of Tourism Research, 2003, 30(1): 238-254.

[21] Boyle, E., Connolly, T. M., \& Hainey, T. (2011). The role of psychology in under- standing the impact of computer games. Entertainment Computing, 2(2), 69-74.

[22] Din H W H. Play to learn: Exploring online educational games in museums. In The 33rd International Conference and Exhibition on Computer Graphics and Interaction Techniques, Boston, MA, 2006.

[23] Sørensen B H, Meyer B. Serious games in language learning and teaching A theorectical perspective. In Proceedings of 3rd International Conference of the Digital Games Research Association, 2007, pp. 559-566.

[24] Annetta L A, Folta E, Klesath, M. V-Learning: Distance Education in the 21st Century through 3D Virtual Learning Environments. Springer, New York, 2010.
[25] Johnson, L.W., Vilhjalmsson, H., Marsella, S. in: Artificial Intelligence in Education, IOS Press, Amsterdam, Netherlands, 2005, pp. 306-313.

[26] de Freitas, S. Learning in immersive worlds, 2006. (http://www.jisc.ac.uk/media/documents/programmes/elearninginnovation/gamingreport_v3.pdf).

[27] Ghiani G, Paternò F, Santoro C, Spano L D. UbiCicero: A location-aware, multi-device museum guide. Interacting with Computers, 2009, 21(4): 288303. 